\title{
Necessidades de informação do operador do direito como usuário do processo judicial eletrônico no estado da Paraíba
}

Rosilene Paiva Marinho de Sousa

Doutora em Ciência da Informação pela Universidade Federal da Paraíba. Especialista em Direito do Trabalho e Processo do Trabalho pelo Centro Universitário de João Pessoa - UNIPÊ Graduação em Ciências Jurídicas e Sociais pela Universidade Federal de Campina Grande e Licenciatura em História pela Universidade Federal de Campina Grande.

Yuri Paulino de Miranda

Pós-graduado pela Escola Superior da Magistratura e concluiu MBA em Direito da Economia e da Empresa pela Fundação Getúlio Vargas (GVLaw). Mestre em Ciência da Informação pela Universidade Federal da Paraíba. Graduação s em Direito.

Marckson Roberto Ferreira de Sousa

Doutor em Engenharia Elétrica na área de Processamento da Informação pela Universidade Federal da Paraíba. Docente do Programa de Pósgraduação em Ciência da Informação da UFPB. Mestrado em Engenharia Elétrica e Graduação em Engenharia Elétrica pela Universidade Federal da Paraíba. Bacharelando em Direito pelo Instituto de Educação Superior da Paraíba. Professor Adjunto do Departamento de Ciência da Informação da UFPB.

Francisca Arruda Ramalho

Bacharelado em Biblioteconomia e Especialização em Sistemas de Bibliotecas Públicas pela Universidade Federal da Paraíba, Mestrado em Administração de Bibliotecas pela Universidade Federal de Minas Gerais e Doutorado em Ciências da Informação pela Universidad Complutense de Madrid, Espanha. Professora Associada do Departamento de Ciência da informação da Universidade Federal da Paraíba.

http://dx.doi.org/10.1590/1981-5344/2598 
Apresenta como escopo, o Processo Judicial Eletrônico (PJe) no Estado da Paraíba, a partir da análise da identificação das necessidades de informação do operador do direito, como usuário do PJe, fazendo-se necessário identificar barreiras de acesso e uso da informação no que diz respeito às necessidades relacionadas ao manuseio das fontes documentais por seus usuários, especificamente, o operador do direito. A pesquisa é exploratória, por se tratar da etapa inicial na estrutura geral de concepção da mesma, levando-se em conta que pouco se sabe sobre os resultados a serem alcançados, pretendendo-se avaliar e identificar as necessidades de informação através de um estudo quanti-qualitativo com um grupo focal. Ela será caracterizada ainda quanto à análise do usuário, pelo direcionamento com respeito ao método moderno ou alternativo de Brenda Dervin, denominado de Sense Making, em que a busca e uso da informação são analisados em termos de situação lacuna cognitiva e de sentido - uso. Desse modo, centra seu foco no ambiente de processamento da informação, em que o comportamento do indivíduo em relação à informação é influenciado pela estratégia para transpor o vazio cognitivo. Ao final, como resultado da pesquisa busca apresentar algumas sugestões de melhoria para o sistema.

Palavras chave: Processo judicial eletrônico; Necessidade de informação; Usuário da informação; Operador do Direito; Abordagem sense making.

\section{Needs of law operator information of Paraíba State as user electronic judicial process}

Features such as scope, the Electronic Judicial Process (PJe) in Paraíba State, from the analysis identifying the information needs of legal operators, as a user of the PJe, necessary to identify barriers to access and use of information in respect of the needs related to the handling of documentary sources in the PJe by its users, specifically, the right operator. The research is exploratory, because it is the initial step in the overall structure of the design of it, taking into account that little is known about the results to be achieved, the objective being to evaluate and identify the information needs 
through a study quanti-qualitative with a focus group. It will still be characterized as an analysis of the user, the direction with respect to modern or alternative method of Brenda Dervin, called Sense Making, in the search and use of information is analyzed in terms of situationcognitive gap and meaning-use. Thus, Center its focus on information processing environment, in which the behavior of the individual in relation to information is influenced by the strategy to overcome the empty cognitive. Finally, as a result of research seeks to present some suggestions for improvement to the system.

Keywords: Electronic judicial process; Information needs; User information; Right operator; Sense making approach.

Recebido em 27.10.2015 Aceito em 02.02.2017

\section{Introdução}

As necessidades dos usuários nem sempre são atendidas por informações que se encontram à sua disposição. Isto ocorre em virtude de que o valor que se atribui à informação depende da relevância atribuída à mesma pelo usuário no momento de sua busca (CHOO, 2003). Durante a sua busca, o usuário pode encontrar diversas barreiras, a saber, restrições de acesso, de tempo, terminologia, interpessoais, legais, que acabam contribuindo para que haja um retardamento, descontentamento ou a não obtenção da informação adequada.

Para a realização de análise dos usos e necessidades de informação pelo usuário torna-se primordial a observância de elementos que a definem, que se baseiam no ambiente no qual a mesma é utilizada e no comportamento em relação à informação. Nesse contexto, a identificação de barreiras de acesso e uso da informação no que diz respeito às necessidades relacionadas ao manuseio de fontes documentais no Processo Judicial Eletrônico por seus usuários (especialmente os advogados), torna-se essencial. Desta forma, a pesquisa centra seu foco na avaliação das necessidades de informação dos operadores do direito como usuários do Processo Judicial Eletrônico e na identificação das barreiras para um efetivo uso do sistema.

A sociedade vem discutindo a questão da lentidão da justiça, trazendo como foco as ações que permitem uma mobilidade no tempo de duração do processo judicial. Pode-se considerar diversos motivos que levam a ocorrência de uma morosidade judicial, sendo possível destacar o relevante formalismo burocrático, demanda acentuada de processos em face da quantidade de informação a ser processada em que não se consegue efetivar uma prestação jurisdicional em tempo satisfatório. Em face desses motivos, torna-se imprescindível uma reforma judiciária que 
permita uma distribuição da justiça em consonância com a realidade social contemporânea. Para que se torne possível a referida reforma, a tecnologia, segundo o pensamento de Wurman (2005), torna-se um instrumento modificador de paradigmas, uma vez que a sociedade é afetada pelo volume vultoso de informação.

O Departamento de Pesquisas Judiciárias do Conselho Nacional de Justiça (CNJ) apresenta o Relatório Justiça em Números 2013, integrante do Sistema de Estatísticas do Poder Judiciário, que expõe dados sobre os números da justiça nacional, divulgados em outubro de 2013, referentes ao ano de 2012. O número de casos pendentes de julgamento no início de 2012 era de 64 milhões de processos, somados aos 28,2 milhões de casos que ingressaram ao longo do ano, chega-se ao total de 92,2 milhões de processos em tramitação em 2012. No estado da Paraíba, apresentou um total de 284.663 novos casos em 2012, implicando em 7.461 novos casos por 100.000 habitantes, apresentando uma estimativa de 544.352 casos pendentes com taxa de congestionamento de 72, 5\% (CNJ, 2013, online).

Demonstra-se uma imprescindível modernização nos diversos aspectos do judiciário, mais especificamente quanto ao aspecto tecnológico, notadamente, a implantação de sistemas de informação que possibilitem tornar menos moroso o trâmite processual, fortalecendo a tendência de utilização de um processo judicial inteiramente eletrônico.

O CNJ amparado pela Lei no 11.419/06 (BRASIL, 2006b) que dispõe sobre a informatização do processo judicial, buscando atender a demanda de processos judiciais nos tribunais brasileiros, elaborou um software denominado de Processo Judicial Eletrônico (PJe). O objetivo principal é manter um sistema capaz de permitir a prática de atos processuais e acompanhamento do processo judicial pelos magistrados, servidores e demais participantes da relação processual com a finalidade de resolver os conflitos existentes. Desse modo, se torna inevitável a ocorrência de mudanças, entre as quais podem se destacar a guarda do processo, inexistência da necessidade de uma tramitação linear, bem como o funcionamento ininterrupto do judiciário.

Considerando a necessidade de modernização do judiciário, em virtude da quantidade de dados a serem processados, e ainda que as necessidades de informação dos usuários e de seus grupos podem variar de acordo com as suas funções ou papéis que eles exercem, o presente estudo apresenta como foco, o Processo Judicial Eletrônico na Paraíba, a partir da análise da identificação das necessidades de informação do operador do direito, como usuários do PJe.

É sob a perspectiva do levantamento e análise de instrumentos jurídicos que amparam o PJe e através da identificação das necessidades de acesso e uso da informação pelo operador do direito como usuário da informação, que a presente proposta deve ser observada. Com efeito, o estudo proposto é um projeto de repercussão social, principalmente em virtude da regulamentação da informatização do processo eletrônico pela Lei no 11.419/06 (BRASIL, 2006b) e também pela Resolução de no 26 de 10 de julho de 2011, que permite a implantação como experiência piloto, 
do sistema Processo Judicial eletrônico nas comarcas da Paraíba, inclusive estabelecendo um calendário de implantação até o final de 2012, conforme Tribunal de Justiça da Paraíba (TJPB, 2011).

A relevância deste trabalho está em trazer ao conhecimento do judiciário e de toda a sociedade, uma visão sobre as necessidades dos usuários em face de um sistema que exige conhecimento prático, embora sua utilização seja relevante para a efetivação de prerrogativas constitucionais no exercício do direito e na prática da cidadania.

\section{Aspectos metodológicos}

A pesquisa pode ser considerada exploratória, por se tratar da etapa inicial na estrutura geral de concepção, levando-se em conta que pouco se sabe sobre os resultados a serem alcançados pela necessidade de informação do operador do direito como usuário do PJe na Paraíba sob a ótica do Direito, visando-se identificar e avaliar necessidades de informação através de um estudo quanti-qualitativo com grupo focal. A pesquisa exploratória é indicada nas situações nas quais as informações sobre o problema em estudo são restritas ou escassas, buscando aumentar o conhecimento sobre o tema pesquisado, esclarecendo conceitos e fornecendo subsídios para as etapas subsequentes de investigação (VERGARA, 2006).

Quanto aos procedimentos é bibliográfica e de campo. Bibliográfica, por ser desenvolvida a partir de material já elaborado, principalmente livros, artigos científicos e material da Internet; e de campo, por ser realizada no local onde se encontram os elementos que explicam o fenômeno estudado (GIL, 2006).

Ela se caracteriza ainda pela análise do usuário, pelo direcionamento com respeito ao método moderno ou alternativo de Brenda Dervin, denominado de Sense Making, que procura lacunas cognitivas e de sentido expressas em forma de questões que podem ser codificadas e generalizadas a partir de dados diretamente úteis para a prática da comunicação e informação (CHOO, 2003; MIRANDA, 2006).

A busca e uso da informação são analisados em termos de situação - lacuna cognitiva e de sentido - uso. Desse modo, centra seu foco no ambiente de processamento da informação, em que o comportamento do indivíduo em relação à informação é influenciado pela estratégia para transpor o vazio cognitivo (CHOO, 2003). Em outras palavras, estabelecese um estudo a partir da relação usuário-lacuna-uso da informação.

A pesquisa sobre Necessidades de Informação do Operador do Direito como Usuário do Processo Judicial Eletrônico na Paraíba trata-se também de uma pesquisa de campo e de cunho exploratório que compreendeu as seguintes etapas:

a)Contato com a Ordem dos Advogados do Brasil (OAB) Seccional da Paraíba, para apreciação do Projeto de Pesquisa e posterior liberação para o desenvolvimento do estudo; 
b)Aceitação do Projeto como pré-teste, para posterior aprofundamento da pesquisa a ser realizada a partir de uma promoção midiática e incentivo à participação de toda classe, para posterior utilização dos resultados pela OAB com 0 objetivo de obter dados concretos para avaliação dos sistemas na Paraíba;

c)Seleção de um questionário semiestruturado como instrumento de coleta de dados, composto de questões fechadas e abertas, relativas à caracterização do perfil dos advogados operadores do direito, as necessidades e usos da informação desses profissionais, assim como as barreiras e/ ou dificuldades encontradas durante o processo de busca e uso da informação, como usuário do processo eletrônico;

d)Aplicação do questionário submetido eletronicamente utilizando-se a Plataforma Google Forms, e disponibilizado através do Informativo $O A B$, sendo que 0 universo a ser estudado ficou composto por 13 advogados. Este procedimento adequou-se à realidade dos advogados e ao Modelo do Sense Making, utilizado para o desenvolvimento da pesquisa;

e)Por fim organizaram-se os dados coletados, os quais foram abordados e analisados, posteriormente, sob a perspectiva dos métodos quantitativo e qualitativo.

\section{Necessidades de informação do operador do direito como usuário do processo eletrônico}

A adoção do processo eletrônico pelo judiciário está se efetivando em todo o país, porém, os usuários para quem é destinado o uso dos sistemas de informação encontram inúmeras barreiras de informação quanto ao manuseio. Segundo Guinchat e Menou (1994), o usuário deve ser considerado como a base da orientação e concepção das unidades e sistemas de informação, sendo as funcionalidades desses sistemas definidas em função de suas características, atitudes, necessidades e demandas.

O PJe é um sistema recente que impulsiona os operadores do direito a adentrarem numa nova área de atuação, a saber, a tecnologia da informação, fazendo-se necessário abordar assuntos como processo eletrônico, utilização de documentos eletrônicos, assinatura digital, chave pública e privada e segurança da informação.

Nos últimos anos os legisladores vêm levando em consideração uma preocupação constante em face do acúmulo de processos a serem julgados em todo o país. Diante do avanço tecnológico e da crescente explosão informacional que vem ocorrendo nos últimos anos, não se torna mais aceitável que um processo se prolongue por anos, de modo que 
venham a se tornar antiquado os procedimentos utilizados nas resoluções das lides.

Diante da necessidade de se avançar na obtenção de resultados das lides, se fez necessário para o legislador transpor as barreiras processuais que originavam a lentidão processual. Historicamente, mudanças elementares no sentido de solucionar o problema da morosidade processual foram vistas no art. 58, inciso IV da Lei no 8.245/91 que passou a permitir que a citação, intimação ou notificação fosse realizada mediante telex ou fac-símile (BRASIL, 1991). Posteriormente, a Lei 9.800/99 possibilitava às partes a utilização de sistema de transmissão de dados para a prática de atos processuais, que mesmo dependendo de petições escritas, não prejudicavam o cumprimento dos prazos, devendo os originais ser entregues em juízo, necessariamente, até cinco dias da data de seu término (BRASIL, 1999). Com a Lei no 10.259/01 em que no art. $8^{\circ}, \S^{\circ}$, que consentia que os tribunais pudessem organizar serviço de intimação das partes e de recepção de petições por meio eletrônico, houve mais um progresso (BRASIL, 2001a). Na sequência, a Medida Provisória no 2.200-2/2001, instituiu-se a Infraestrutura de Chaves Públicas Brasileira (ICP-Brasil), objetivando assegurar a autenticidade, a integridade e a validade jurídica de documentos em forma eletrônica (BRASIL, 2001b). A Lei no 11.280/06 alarga o quadro estabelecendo no parágrafo único do art. 20 , que os tribunais passariam a disciplinar a prática e a comunicação oficial dos atos processuais por meios eletrônicos (BRASIL, 2006a). Contudo, foi a Lei 11.419/06 que segundo Castro e Allemand (2014) veio a encerrar o ciclo de normas jurídicas voltadas para a informatização completa do processo judicial no Brasil, tornando-se regra à tramitação de autos no meio eletrônico, pois passou a admitir o uso de meio eletrônico na tramitação de processos judiciais, comunicação de atos e transmissão de peças processuais (BRASIL, 2006b). Uma considerável transformação para os operadores do direito surgiu com a referida lei, na medida em que passa a regulamentar o uso da assinatura digital nos Tribunais, o estabelecimento de prazos com acesso de até 24 horas por dia, a intimação e a citação por meio eletrônico. Tornou-se possível afirmar que houve uma verdadeira mudança de paradigma.

Levando-se em consideração essa evolução, progrediu-se da petição escrita por próprio punho à máquina de escrever, à máquina elétrica, ao computador e a Internet, estando o PJe centrado como uma consequência desse processo.

Embora o processo eletrônico tenha surgido para facilitar o acesso à justiça, obter celeridade no trâmite processual, transparência, redução de custos, entre outros aspectos benéficos, deve-se considerar que as transições exigem aperfeiçoamento. Segundo Castro e Allemand (2014, p. 30), "embora sejam promissoras as perspectivas do PJe, são consideráveis as preocupações com as imprescindíveis providências para uma transição minimamente segura e tranquila do 'velho' processo físico para o 'novo' processo eletrônico". Segundo os referidos autores, verificase uma atuação crescente e iniciativas da Ordem dos Advogados do Brasil 
no sentido de pugnar por ajustes para que haja sempre um bom andamento dos processos com auxilio da Tecnologia da Informação.

Para Pinto (2014), modus omnibus in rebus - em todas as coisas deve haver uma medida - uma vez que o Poder Judiciário deve insistir na informatização do processo, desde que não imponha prejuízos irreversíveis as partes e aos advogados. O referido autor acrescenta ainda que não parece justo submeter o processo à Tecnologia da Informação, antes de todos os interessados se encontrem habilitados a usá-la.

Nesse contexto, deve-se levar em consideração o usuário, que no caso do PJe, trata-se do operador do direito, que é essencial na concepção, avaliação, adaptação, estímulo e funcionamento de qualquer sistema de informação no âmbito jurídico. Verifica-se que "[...] é necessário proporcionar ao usuário não só a capacidade de entender suas próprias necessidades de informação, mas também satisfazê-las e, se possível, com seus próprios meios" (MIRANDA, 2006, p. 99).

O PJe estabelece que o operador do direito e demais participantes do processo judicial trabalhem com a tecnologia, adaptando-se a uma série de modificações quanto a realização do processo judicial, onde segundo o Conselho Nacional de Justiça "[...] um dos grandes calcanhares dos sistemas processuais eletrônicos é a visualização do processo. Sair de um encarte de peças processuais sequenciais para uma sequência de cliques e janelas múltiplas é doloroso para quem lida tradicionalmente com processos judiciais" (CNJ, 2010, p. 16).

Neste sentido, novos conceitos são envolvidos para utilização do PJe que precisam ser familiarizados pelos juristas. Conforme a Autoridade Certificadora da Ordem dos Advogados do Brasil (AC - OAB, 2014, online) o Certificado Digital é uma credencial que identifica uma empresa ou pessoa física na Internet, permitindo que o titular assine digitalmente qualquer tipo de documento e realize transações eletrônicas com segurança, rapidez e validade jurídica. A referida autoridade certificadora expõe que a assinatura digital é um instrumento que permite conferir o autor e a integridade do documento eletrônico, garantindo que o documento não tenha sofrido qualquer modificação depois de assinado digitalmente. Também explica que a conferência de uma assinatura digital é realizada de forma que um conjunto de Chaves Públicas e Privadas, baseado na tecnologia de criptografia assimétrica, em que a chave privada é utilizada para cifrar o resumo (hash) obtido a partir do documento que se deseja assinar, e a chave pública para decifrar a Assinatura Digital, comparando-a com o resumo do documento em análise.

O documento eletrônico corresponde a um documento gerado e mantido em sua forma eletrônica, sem a necessidade de ser impresso em papel ou assinado manualmente para ter valor. Assim, o vínculo deste documento com o seu autor é estabelecido por meio da assinatura digital. Neste sentido, recomenda-se não confiar a guarda e o empréstimo do Certificado Digital ou senhas a terceiros, pois a sua assinatura digital possui a mesma validade legal que a sua assinatura manuscrita. Isto 
porque segundo a AC - OAB (2014, online) não há meios técnicos de distinguir as geradas pelo titular ou por terceiros.

Essas adequações necessárias aos operadores do direito são indispensáveis, pela obrigação estabelecida em lei de credenciamento prévio no Poder Judiciário para o exercício da profissão, além de que a Lei $11.419 / 06$ em seu Art. 10, $\S 1^{0}$, ressalta que a aplicação do dispositivo se dará indistintamente, aos processos civil, penal e trabalhista, bem como aos juizados especiais, em qualquer grau de jurisdição (BRASIL, 2006b).

Na Comarca de João Pessoa, a Resolução no 26 de 01 de julho de 2011, estabelece em seu art. $8^{\circ}$ que o credenciamento no PJe será efetuado pela diretoria de tecnologia da informação, para os usuários internos, e, no portal do Tribunal de Justiça da Paraíba pelo próprio usuário externo. Segundo o art. 60, inciso II, da Resolução no 26, 0 operador do direito (advogado), enquadra-se como usuário externo, tendo, de acordo com o art. 70, acesso às funcionalidades do PJe de acordo com o perfil atribuído em função de sua posição na relação jurídico-processual (TJPB, 2011).

Nos termos da Resolução no $185 / 2013$ do Conselho Nacional de Justiça, a implantação do PJe deve ocorrer em pelo menos $10 \%$ das unidades judiciais do Estado, envolvendo unidades com competências diversificadas com a finalidade de ganhar experiência e garantir uma expansão segura e efetiva (TJPB, 2014).

Diante do exposto, a informação necessária e adequada no tempo certo, podem ser obtidas através do PJe, mas que necessita da realização de determinados procedimentos corretos para o funcionamento adequado do sistema.

\section{Relato da pesquisa sobre necessidades de informação do operador do direito no uso do PJe}

Nesta seção serão apresentados os dados obtidos a partir da etapa de coleta de dados realizada por meio de um questionário disponibilizado na World Wide Web.

\subsection{Perfil do usuário}

O questionário foi realizado sob a forma de formulário eletrônico na Plataforma Google Forms, conforme demostrado na Figura 1, podendo os participantes, após acessar o questionário, optar por participar ou não da pesquisa. 


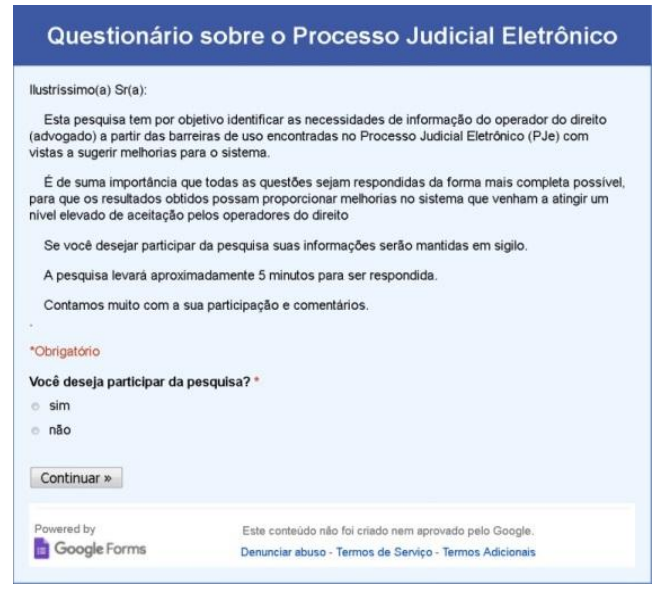

Figura 1 - Questionário sobre Processo Judicial Eletrônico

Fonte: Dados da pesquisa.

Foram 13 (treze) os participantes, tendo todos, optado por responder às questões através do formulário eletrônico. Ao escolher a opção continuar, os participantes passaram à responder o questionário a partir da identificação do perfil do usuário. A primeira questão consistia na identificação opcional dos participantes, em que dos treze respondentes, 10 (dez) identificaram os seus respectivos números de inscrição na OAB.

Quanto à idade constatou-se que 38,47\% têm idade superior a cinquenta anos, seguindo-se pelos que apresentam idade entre 25 e 30 anos, correspondendo a 30,77\% dos entrevistados, as faixas de 31 a 40 anos e 41 a 50 anos tiveram 15,38\%, não sendo, contudo constatado a participação de respondentes na faixa inferior a 25 anos.

Entre os treze participantes, 11 (onze) são do sexo masculino, correspondendo a $84,6 \%$ dos participantes, e 2 (dois) do sexo feminino, correspondendo a $15,4 \%$ dos respondentes.

Quanto ao nível de Escolaridade dos Advogados, 46,1\% tem nível de especialização, seguido de 38,5\% apenas com Graduação e 15,4\% com Doutorado, não registrando nenhum dos respondentes com nível de Mestrado ou Pós Doutorado, conforme mostrado no Gráfico 1.

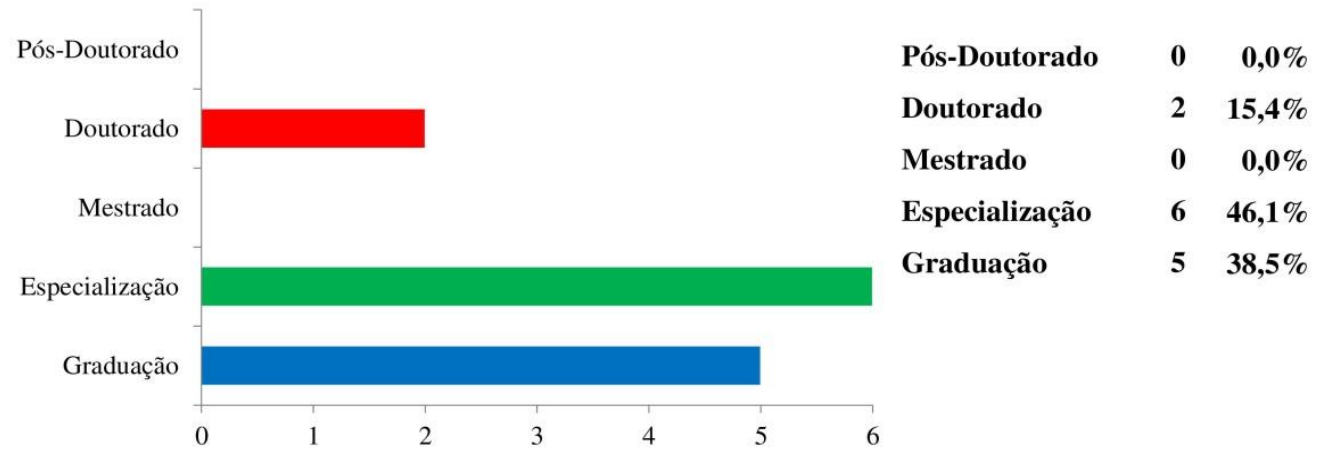

Gráfico 1 - Nível de escolaridade

Fonte: Dados da pesquisa. 
Foram identificadas algumas áreas de atuação como administrativo, ambiental, criança e do adolescente, penal, previdenciário, sendo que o maior destaque se deu na área cível, seguida da área trabalhista.

Foram registrados quanto à Comarca de exercício da profissão, que dos treze participantes, 69,2\% atuam na Comarca de João Pessoa, e $7,7 \%$ igualmente em cada uma das cidades de Agua Branca, Bayeux, Cajazeiras e Itabaiana.

No quesito tempo de exercício da profissão, 46,1\% tem menos de 5 (cinco) anos de atuação, seguido por 30,8\% com mais de 15 anos, de $15,4 \%$ entre 5 (cinco) e 10 (dez) anos e 7,7\% de 11 (onze) a 15 (quinze) anos de atuação, conforme mostrado no Gráfico 2.

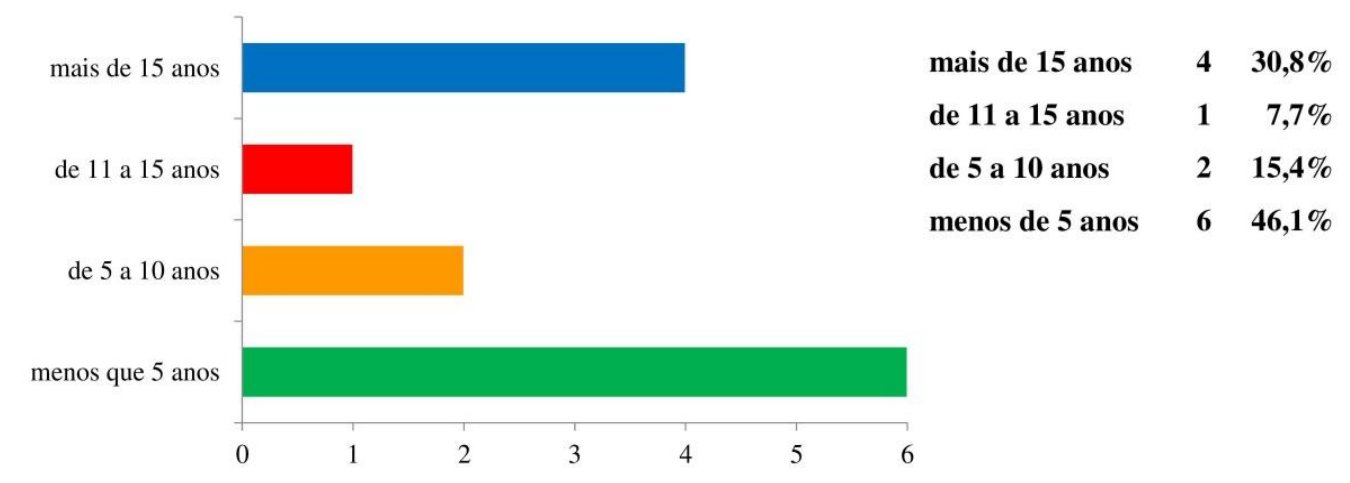

Gráfico 2 - Tempo de Exercício da Profissão

Fonte: Dados da pesquisa.

Quanto aos órgãos do Poder Judiciário em que os advogados utilizam os respectivos sistemas, destacaram-se a Justiça Estadual bem como o Juizado Especial, seguido da Justiça do Trabalho e Justiça Federal.

Na sequência buscou-se conhecer através da análise e discussão dos resultados, as reais necessidades e usos informacionais, dos operadores do direito (advogados), assim como, as barreiras encontradas ao utilizar os sistemas.

\subsection{Necessidades e uso da informação}

Com o objetivo de diagnosticar as necessidades e uso da informação através do processo Judicial Eletrônico, verificou-se através do formulário eletrônico, a frequência com que o PJe é usado pelo advogado. Como resultado tem-se que $46,1 \%$ dos respondentes utilizam todos os dias, seguido pelos que utilizam duas os três vezes por semana $(23,1 \%)$, e de apenas $7,7 \%$ utilizam apenas uma vez no mês. Os demais $23,1 \%$ não utilizam, além disso, observou-se que nenhum dos respondentes utilizou apenas uma vez por semana, conforme demostrado no Gráfico 3. 


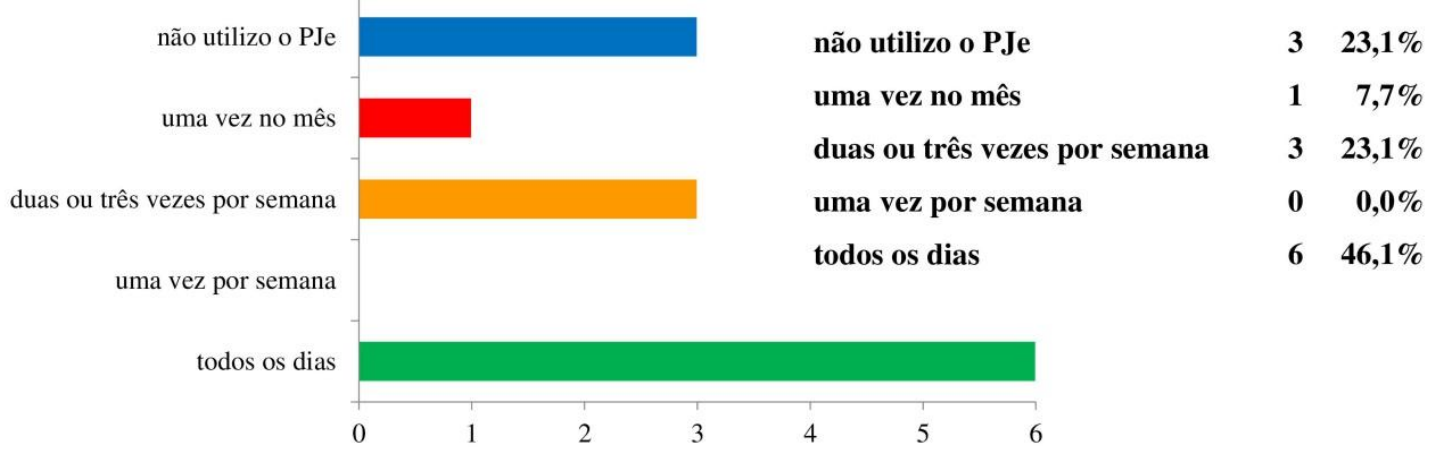

Gráfico 3 - Frequência de Uso do Processo Judicial Eletrônico - PJe

Fonte: Dados da Pesquisa

Neste cenário foram questionados os motivos pelos quais não utilizam o sistema. Como resposta foram apontados os seguintes motivos: "Porque ainda estou concluindo o certificado digital"; "Ainda não me cadastrei, e não tenho nenhum processo nas Varas onde atualmente funciona o PJe" ou que ainda não foi preciso.

Constou também do formulário uma pergunta indagando se no ambiente de trabalho do advogado, outras pessoas (estagiários, sócios, entre outros) acessam o PJe, sendo que 46,2\% afirmaram que sim, e $53,8 \%$ afirmaram que outras pessoas não acessam o PJe no seu ambiente de trabalho. Solicitou-se também que, em caso de resposta positiva, fosse justificada a resposta. Desta forma, foi apontado que além do respondente, outras pessoas como sócios e advogados contratados, estagiários, funcionários do escritório também utilizavam o sistema. Destacando-se que um dos respondentes afirmou que é assessorado por pessoa que utiliza o sistema de informática, na sua fala: "A pessoa é o meu assessor que é estudante universitário da área de informática, vem dois dias na semana".

Constatou-se também que $69,2 \%$ dos advogados participantes possuíam Certificação Digital, enquanto 30,8\% ainda não têm. Quanto à dificuldade em converter um arquivo para formato "pdf" 84,6\% afirmaram não ter dificuldade, e $15,4 \%$ afirmaram ter. A estes, foi pedido que justificasse o motivo, havendo destaque ao posicionamento de que encontra dificuldade por falta de familiaridade com a informática, além dos problemas que envolvem o funcionamento do sistema, conduzindo a preocupações em virtude dos prazos estabelecidos para a realização dos atos processuais.

\subsection{Situação recente de uso da informação}

Levando-se em consideração que a pesquisa se detém a examinar as expectativas e comportamentos informacionais do operador do direito (advogado) como usuário do Processo Judicial Eletrônico, foram avaliadas algumas questões relacionadas à situação recente de uso da informação. 
Necessidades de informação do operador do direito como usuário do processo judicial eletrônico no estado da Paraíba
Rosilene Paiva Marinho de Sousa; Yuri Paulino de Miranda; Marckson Roberto Ferreira de Sousa; Francisca Arruda Ramalho

Neste sentido, no Quadro 1 são demostradas as principais situações e sugestões expostas pelos participantes.

\section{Quadro 1 - Situação Recente de Uso da Informação}

\begin{tabular}{|c|c|}
\hline Quesitos & Principais Respostas \\
\hline $\begin{array}{l}\text { Em que fase do procedimento processual } \\
\text { você encontra maior dificuldade na utilização } \\
\text { do PJe? }\end{array}$ & $\begin{array}{l}-\quad \text { no protocolo de petições iniciais; } \\
\text { - } \quad \text { na hora de cadastrar as partes e de concluir o } \\
\text { procedimento porque o sistema costuma cair }\end{array}$ \\
\hline $\begin{array}{l}\text { Que barreiras/obstáculos (tempo, acesso ao } \\
\text { sistema, termos técnicos, qualidade, } \\
\text { excesso e restrições da informação, uso dos } \\
\text { recursos tecnológicos, dentre outros) } \\
\text { surgiram no decorrer da utilização do } \\
\text { sistema? }\end{array}$ & $\begin{array}{l}\text { - o sistema sair do ar durante o uso, perdendo todo } \\
\text { trabalho já feito; } \\
\text { - a maior dificuldade é no tempo gasto para inserir } \\
\text { documentos; } \\
\text { - o sistema apresenta sempre mensagens de erro; } \\
\text { - o travamento do acesso, o retorno a página anterior, } \\
\text { a utilização de um navegador de Internet específico para cada } \\
\text { sistema e cada procedimento a ser utilizado }\end{array}$ \\
\hline $\begin{array}{l}\text { Descreva, o problema/situação, encontrado } \\
\text { mais recentemente na utilização do PJe }\end{array}$ & $\begin{array}{l}\text { indisponibilidade do sistema; } \\
\text { - } \quad \text { a indisponibilidade do sistema geralmente após os } \\
\text { expedientes e a limitação quanto ao tamanho dos arquivos; } \\
\text { - } \quad \text { no navegador GOOGLE CHROME, não se completa } \\
\text { a operação de cadastramento da ação; } \\
\text { - } \quad \text { o editor de texto tem poucos recursos; } \\
\end{array}$ \\
\hline $\begin{array}{l}\text { Que estratégias de busca de informação } \\
\text { você utilizou para solução do seu } \\
\text { problema/situação? }\end{array}$ & $\begin{array}{ll}- & \text { a maioria busca contato com o } \text { TJPB }^{1} ; \\
\text { - } & \text { esperar o sistema voltar a funcionar normalmente; } \\
\text { - } & \text { paciência; } \\
\text { - } & \text { rezar; }\end{array}$ \\
\hline $\begin{array}{l}\text { Quando você estava buscando a informação } \\
\text { quais as dúvidas receios/anseios/ } \\
\text { expectativas) que lhe ocorreram? }\end{array}$ & $\begin{array}{l}\text { - } \quad \text { do problema não ser resolvido a tempo; } \\
\text { - } \quad \text { a indisponibilidade com repercussão no prazo; } \\
\text { - } \quad \text { que não teria acesso ao mesmo, e ficaria sem saber } \\
\text { o andamento dos processos; } \\
\text { - } \quad \text { que a apreensão seria superada com o sucesso da } \\
\text { iniciativa necessária. Mas quase sempre deixou de ser; }\end{array}$ \\
\hline $\begin{array}{l}\text { Você saiu satisfeito com as informações } \\
\text { obtidas a partir do sistema (PJe)? }\end{array}$ & $\begin{array}{l}\text { - sim: ciente da necessidade de treinar o seu } \\
\text { funcionamento; na busca de informações sobre os processos } \\
\text { cadastrados; } \\
\text { • não: O sistema não fornece automaticamente } \\
\text { relatório de indisponibilidade; sempre recorrer ao TJPB; } \\
\text { sistema inoperante; mais informações e treinamentos; sistema } \\
\text { não explicativo; falta de software para comprimir os arquivos, } \\
\text { impressoras virtuais, que poderiam estar no próprio Tribunal; }\end{array}$ \\
\hline
\end{tabular}

Fonte: Dados da pesquisa.

Como sugestões foram apontados: uma maior automação do sistema, respeitando o estatuto do idoso; ouvir os operadores do direito que utilizam o sistema, no caso, os advogados, pois só assim irá conseguir melhorar o sistema; haver treinamento dos operadores para melhor utilização; sugestão de elaboração de um FAQ (Frequently Asked Questions ou Questões Frequentemente Formuladas) que possibilite resolver as dúvidas que surgem de forma mais rápida e em linguagem simples, sem utilização do "informatiquês"; implantação de formas de uma melhor visualização por meio de celulares e tablets.

\footnotetext{
${ }^{1}$ TJPB refere-se ao Tribunal de Justiça da Paraíba.
} 


\section{Considerações finais}

Nesta pesquisa realizou-se uma análise sobre a utilização do Processo Judicial Eletrônico na Paraíba buscando identificar as necessidades de informação do operador do direito a partir das barreiras informacionais encontradas, com vistas a sugerir melhorias para o sistema.

Nos diversos aspectos da vida humana a tecnologia da informação tem tornado possível à realização de transformações nos processos, permitindo uma reconfiguração frente às compreensões do mundo real e como o virtual pode ser incorporado, além da eliminação de barreiras referente ao tempo e espaço.

O campo do direito necessita acompanhar as mudanças sociais, onde o operador do direito reconhece dificuldades quanto a essas mudanças, posto que foge ao domínio intrínseco no exercício de suas funções. Evidencia-se uma discrepância em discernir a tecnologia como uma ameaça, visto que a tecnologia se aplicada adequadamente para o fim a que a se destina, qual seja, de facilitar e agilizar a atividade humana, retira uma visão obscura. Uma concepção equivocada elimina a existência de processos que possibilitem o acesso e a harmonia que deve ser estabelecidos entre os domínios humano e tecnológico.

A partir dos dados obtidos nesta pesquisa, onde foram examinadas as necessidades de informação do operador do direito, foram obtidos dados quantitativos relacionados ao perfil dos usuários e as dificuldades foram identificados quanto ao uso do PJe, sendo possível inclusive tecer sugestões para a realização de melhorias baseadas nas necessidades de informação percebidas.

Com a utilização de sistemas mais elaborados e adequados à realidade dos operadores do direito, vislumbra-se facilitar a ubiquidade necessária à interligação do real com o virtual. Porém, torna-se imprescindível pensar sobre os caminhos a serem seguidos, para que os operadores do direito possam ter as relações entre o humano $e$ computador facilitadas.

\section{Referências}

AUTORIDADE CERTIFICADORA - ORDEM DOS ADVOGADOS DO BRASIL (AC - OAB). Certificado Digital OAB: vantagens que todo advogado precisa conhecer. 2014.2 Disponível em: < http://www.acoab.com.br/pdf/AF 317 folder OAB A5 baixa final.pdf $>$.

Acesso em: 15 set. 2015.

BRASIL. Lei 8.245 , de 18 de outubro de 1991. Dispõe sobre as locações dos imóveis urbanos e os procedimentos a elas pertinentes. Diário Oficial da União, Brasília, 21 de outubro de 1991. 
BRASIL. Lei 9.800, de 26 de maio de 1999. Permite às partes a utilização de sistema de transmissão de dados para a prática de atos processuais. Diário Oficial da União, Brasília, 27 de maio de 1999.

BRASIL. Lei 10.259, de 12 de julho de 2001. Dispõe sobre a instituição dos Juizados Especiais Cíveis e Criminais no âmbito da Justiça Federal. Diário Oficial da União, Brasília, 13 de julho de 2001a.

BRASIL. Medida Provisória 2.200-2, de 24 de agosto de 2001. Institui a Infra-Estrutura de Chaves Públicas Brasileira - ICP-Brasil, transforma o Instituto Nacional de Tecnologia da Informação em autarquia, e dá outras providências. Diário Oficial da União, Brasília, 27 de agosto de 2001b.

BRASIL. Lei 11.280 de 16 de fevereiro de 2006. Altera os arts. 112,114 , 154, 219, 253, 305, 322, 338, 489 e 555 da Lei no 5.869, de 11 de janeiro de 1973 - Código de Processo Civil, relativos à incompetência relativa, meios eletrônicos, prescrição, distribuição por dependência, exceção de incompetência, revelia, carta precatória e rogatória, ação rescisória e vista dos autos; e revoga o art. 194 da Lei no 10.406, de 10 de janeiro de 2002 - Código Civil. Diário Oficial da União, Brasília, Brasília, 17 de fevereiro de 2006a.

BRASIL. Lei 11.419, de 19 de dezembro de 2006. Dispõe sobre a informatização do processo judicial; altera a Lei no 5.869, de 11 de janeiro de 1973 - Código de Processo Civil; e dá outras providências. Diário Oficial da União, Brasília, 20 de dezembro de 2006b.

CASTRO. A. A.; ALLEMAND, L. C. Transição segura do processo judicial eletrônico é possível? Revista Jurídica Consulex, ano 18, v. 1, n. 409, fev. 2014.

CHOO, C. W. A organização do conhecimento: como as organizações usam informação para criar significado, construir conhecimento e tomar decisões. São Paulo: SENAC, 2003.

CONSELHO NACIONAL DE JUSTIÇA (CNJ). Justiça em números 2013. 4. ed. Brasília, DF: Gráfica do Conselho da Justiça Federal, 2013. Disponível em: $<$ http://www.cnj.jus.br/images/pesquisas-

judiciarias/Publicacoes/relatorio in2013.pdf > . Acesso em: 15 set. 2015.

CONSELHO NACIONAL DE JUSTIÇA (CNJ). Processo judicial eletrônico. Brasília, DF: [s.n.], 2010. Disponível em: <http://www.cjf.jus.br/pjeif/manuais/Cartilha\%20do\%20PJe.pdf>. Acesso em: 15 set. 2015.

GIL, A. C. Métodos e técnicas de pesquisa social. 5. ed. São Paulo: Atlas. 2006.

GUINCHAT, C.; MENOU, M. Introdução geral às ciências e técnicas da informação e documentação. 2. ed. Brasília: IBICT, 1994.

MIRANDA, S. Como as necessidades de informação podem se relacionar com as competências informacionais. Ciência da Informação, Brasília, v. 35, n. 3, p. 99-114, set./dez. 2006. 
PINTO, A. P. Processo judicial eletrônico: modus omnibus in rebus. Revista Jurídica Consulex, ano 18, v. 1, n. 409, fev. 2014.

TRIBUNAL DE JUSTIÇA DA PARAÍBA (TJPB). Resolução no 26, de 1 de julho de 2011. Implanta, como experiência piloto o sistema processo judicial eletrônico - PJe na $3^{a}$ Vara Mista da Comarca de Bayeux, restrito aos fetos de família; nas $3^{a}$ e $4^{a}$ Varas da Comarca de Cabedelo, restrito aos feitos executivos fiscais; no Juizado Especial Misto da Comarca de Santa Rita, restrito aos feitos cíveis; e na $2^{a}$ Vara da Comarca de Itabaiana, restrito aos feitos da infância e da juventude, e dá outras providências. Diário Oficial do Estado, João Pessoa, 2 de julho de 2011.

TRIBUNAL DE JUSTIÇA DA PARAÍBA (TJPB). Tribunal de Justiça executa implantação e expansão do Processo Judicial Eletrônico no Estado. 2014. Disponível em: <http://www.tjpb.jus.br/ tribunal-de-justica-executa-implantacao-eexpansao-do-processo-judicial-eletronico-no-estado/>. Acesso em: 11 set. 2015. VERGARA, S. C. Projetos e relatórios de pesquisa em administração. São Paulo: Atlas, 2006.

WURMAN, R. S. Ansiedade da informação 2: um guia para quem comunica e dá instruções. São Paulo: Cultura, 2005. 